
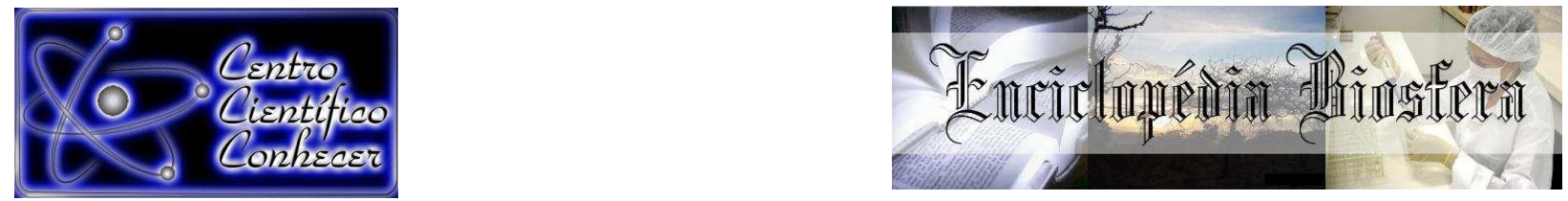

\title{
VIABILIDADE PÓLINICA EM Bertholletia excelsa Bonpl. (LECYTHIDACEAE) BASEADA EM DIFERENTES TESTES COLORIMÉTRICOS
}

Taynara Antunes dos Santos ${ }^{1}$; Poliana Vicente Tiago ${ }^{2}$; Kátia Fabiane Medeiros Schmitt $^{1}$; Kellen Coutinho Martins ${ }^{3}$; Ana Aparecida Bandini Rossi ${ }^{4}$

${ }^{1}$ Graduandas de Ciências Biológicas, Universidade do Estado de Mato Grosso - UNEMAT, Campus de Alta Floresta, MT. e-mail:

taynara.nb@hotmail.com

${ }^{2}$ Mestranda do Programa de Pós-Graduação em Biodiversidade e Agroecossistemas Amazônicos - PPGBioAgro, Universidade do Estado de Mato Grosso - UNEMAT, Campus de Alta Floresta, MT.

${ }^{3}$ Pós - doutora do Programa de Pós-Graduação em Biodiversidade e Agroecossistemas Amazônicos - PPGBioAgro, UNEMAT, Campus de Alta Floresta, MT.

${ }^{4}$ Doutora em Genética e Melhoramento. Laboratório de Genética vegetal e Biologia Molecular. Professora da Faculdade de Ciências Biológicas e Agrárias, PPGBioAgro, PGMP e PPG - Bionorte / UNEMAT, Campus de Alta Floresta, MT, Brasil.

Recebido em: 08/09/2015 - Aprovado em: 14/11/2015 - Publicado em: 01/12/2015 DOI: http://dx.doi.org/10.18677/Enciclopedia_Biosfera_2015_030

\section{RESUMO}

O presente estudo teve como objetivo estudar a viabilidade dos grãos de pólen de genótipos de Bertholletia excelsa, utilizando três diferentes corantes (carmim acético, lugol e Alexander) para determinar o mais indicado para avaliar a viabilidade polínica. Botões florais foram coletados e preparados para visualização em lâminas. Onde foram contados os grãos de pólen viáveis e inviáveis, os resultados foram submetidos a análise de variância e as médias comparadas pelo teste de Scott Knott a $5 \%$ de probabilidade respectivamente. Independente do corante utilizado, em nenhum dos genótipos houve maior número de grãos de pólen estéreis/inviáveis; ao contrário, foram verificadas altas porcentagens de grãos de pólen viáveis. Analisando a influência de cada corante na estimativa da viabilidade, observou-se que a média de viabilidade do corante Carmim foi menor do que as análises realizadas com os demais corantes. Mesmo não havido diferença significativa entre as soluções Lugol e Alexander, o corante Alexander mostrou resultado mais satisfatório, podendo ser indicado, visto que é o que melhor discrimina os grãos de pólen viáveis dos inviáveis.

PALAVRAS-CHAVE: castanha do Brasil; grãos de pólen; viabilidade polínica.

\section{ESTIMATION OF POLLEN VIABILITY OF Bertholletia excelsa Bonpl. (LECYTHIDACEAE) Based In Different Colorimetric Tests}

\begin{abstract}
The present study aimed to study the viability of pollen grains of Bertholletia excelsa genotypes using three different dyes (acetic carmine, lugol and Alexander) to determine the most suitable to assess the pollen viability. Flower buds were collected
\end{abstract}


on slides prepared for viewing. Where were counted the viable and non-viable pollen grains, the results were submitted to variance analysis and the averages compared by Scott Knott test at $5 \%$ probability respectively. Regardless of the dye used in any of the genotypes there was a higher number of non-viable pollen grains; on the contrary, they were found high percentages of viable pollen grains. Analyzing the influence of each dye in the estimation of viability, it was observed that the average viability of carmine dye was smaller than analyzes with other dyes. Even no significant difference between lugol and Alexander solutions, the dye Alexander showed more satisfactory result and may be indicated, since it is the best discrimination viable pollen grains of unviable.

KEYWORDS: Brazil-nuts; pollen grains; pollen viability

\section{INTRODUÇÃO}

Bertholletia excelsa Bonpl. pertence à família Lecythidaceae e é considerada uma das espécies de maior valor econômico da floresta Amazônica (CAMARGO, 2010). Sua exploração desempenha papel fundamental na organização socioeconômica de grandes áreas extrativistas, representando importante componente na pauta de exportação da região amazônica (ANGELO et al., 2013).

Os frutos de $B$. excelsa são conhecidos como "castanha do Brasil", "castanha do Pará" ou "castanha da Amazônia" e despertam interesse, entre outros fatores, devido ao seu alto valor nutritivo. Segundo COSTA (2011), a castanha é um alimento fundamental para a alimentação humana e de várias espécies de animais, podendo ser também uma fonte de óleos vegetais de alta qualidade. Além disso, a madeira da castanheira pode ser utilizada na construção civil e naval, como forros, paredes, assoalhos, entre outros (COSTA, 2011).

A castanheira do Brasil representa a única espécie existente no gênero Bertholletia (SALOMÃO, 2014), apresentando considerável variação no tamanho, forma e número de sementes por fruto (MORI \& PRANCE, 1990). A espécie ocorre na Venezuela, Colômbia, Peru, Bolívia e Guianas, mas no Brasil existe em maior número e formações compactas, nos estados do Pará, Amazonas, Acre, Maranhão, Mato Grosso, Rondônia, Amapá e Roraima (SMITH et al., 2015).

A ecologia ambiental em que essa espécie se encontra é de grande importância para propor medidas preservacionistas nas áreas de ocorrência, além de estabelecer sistemas de cultivo economicamente viáveis e ecologicamente adequados (CAMARGO, 2010). A floração da castanheira-do-Brasil é anual, longa, sincrônica e ocorre predominantemente durante a época de menor precipitação por um período médio de seis meses (TONINI, 2011). O período reprodutivo é uma fase de grande importância para a dinâmica das populações e para a própria sobrevivência das espécies. As informações sobre viabilidade polínica são fundamentais para trabalhos de biologia reprodutiva, contribuindo para estudos ecológicos e taxonômicos da espécie em estudo, fornecendo informações que podem ser utilizadas em processos de conservação genética, assim como na agricultura e em programas de melhoramento.

Por meio de estudos sobre a viabilidade polínica pode-se estimar o potencial de reprodução de uma espécie, cultivar ou população. Muitas espécies produzem elevado percentual de pólen viável, no entanto nem todos são utilizados na fertilização efetivamente, sendo perdidos pelo transporte através do vento ou na alimentação de insetos, desta forma quanto mais alta for a viabilidade polínica, maior será o sucesso da fertilização (MARTINS et al., 2012). 
Considerando-se a função do grão de pólen no ciclo de vida de uma planta, uma maneira de testar a viabilidade polínica seria realizar a polinização e, posteriormente, analisar a frutificação. No entanto, devido ao tempo que essa atividade leva, outros métodos são frequentemente usados (KARAKAYA, 2011).

Neste sentido, o presente trabalho teve como objetivo avaliar a viabilidade polínica em espécimes de $B$. excelsa distribuídos em populações naturais no norte do estado de Mato Grosso, por meio do uso de diferentes corantes, a fim de fornecer subsídios para a conservação in situ da espécie.

\section{MATERIAL E MÉTODOS}

As coletas foram realizadas no ano de 2013 nos meses de outubro a dezembro, durante a primavera, a temperatura média anual no município varia de $19,6^{\circ} \mathrm{C}$ a $32,4^{\circ} \mathrm{C}$ e as precipitações no período de maio a setembro variam entre 250 a $300 \mathrm{~mm}$ e nos meses de outubro a abril de 900 a 1000mm (TARIFA, 2011). Botões florais foram coletados em 20 espécimes de Bertholletia excelsa Bonpl provenientes de quatro localidades no município de Alta Floresta, norte do estado de Mato Grosso, sendo: seis indivíduos na comunidade Sol Nascente, quatro na comunidade Ouro Verde, cinco na comunidade Central (Estrada Central) e cinco no Jardim das Araras (Chácara Esteio) (Figura 01).

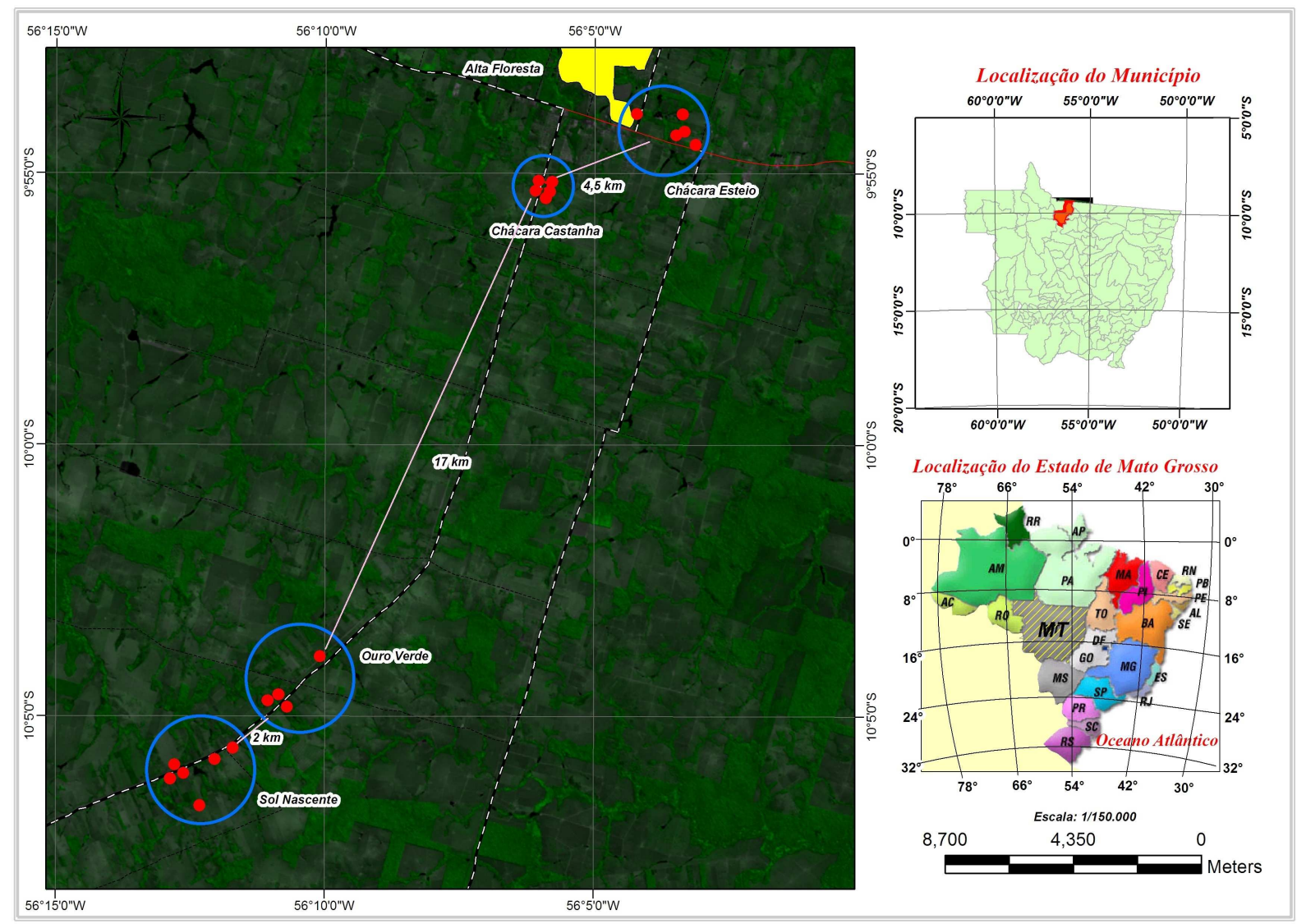

FIGURA 01. Localização das áreas de estudo: Detalhe da localização geográfica de cada espécime amostrado nas quatro localidades. = Espécimes de $B$. excelsa amostradas em cada localidade.

Para a estimativa da viabilidade polínica foi coletado um mix de 15 botões florais para cada um dos 20 indivíduos, distribuídos nas quatro localidades. Os 
botões florais foram coletados por volta das 7:00 horas da manhã e fixados em solução de etanol e ácido acético na proporção 3:1. Apos $24 \mathrm{~h}$ foram transferidos para uma solução de álcool $70 \%$ e conservados em geladeira. Foram testados três diferentes corantes: carmim acético (KEARNS \& INOUYE 1993) cor vermelha para pólens viáveis; lugol (DAFNI, 1992) pólens viáveis ficam marrons e Alexander (ALEXANDER, 1969), em que os grãos de pólen viáveis ficam da cor vermelha ou púrpura no protoplasto, enquanto que os inviáveis apresentam coloração verde.

Foram preparadas cinco lâminas de cada um dos vinte mix (indivíduos), para cada um dos três corantes (carmim acético, Alexander e lugol). No preparo das lâminas as anteras foram cortadas transversalmente com o auxílio de um bisturi sendo posteriormente maceradas levemente com um escalpelo, para à liberação dos grãos de pólen sobre $10 \mu \mathrm{L}$ do corante testado. Após a retirada dos debris, o material foi coberto com uma lamínula e observado ao microscópio.

O método de observação foi o de varredura, com a contagem de cinco lâminas para cada indivíduo em cada corante. Em cada lâmina contou-se 500 grãos de pólen, perfazendo um total de 2.500 grãos de pólen por espécime. Todas as lâminas foram observadas sob microscópio óptico Primo Star Zeiss (10x) e as imagens foram digitalizadas utilizando o fotomicroscópio Leica DMLB, acoplado à câmera digital.

Os resultados da estimativa da viabilidade polínica foram submetidos à análise de variância pelo teste Scott-Knott em nível de 5\% de probabilidade, para comparação entre as localidades e entre corantes. As análises estatísticas foram realizadas com o auxílio do programa Genes (CRUZ, 2008).

\section{RESULTADOS E DISCUSSÃO}

Independente do corante utilizado, a espécie $B$. excelsa apresentou uma alta taxa de pólen viável, sendo a média geral para cada corante superior a $85 \%$ (Tabela 1). A fertilidade de uma espécie é normalmente medida via viabilidade polínica, que indica a formação de gametas normais e balanceados (MARTINS, 2010).

TABELA 1: Valores médios percentuais de viabilidade do pólen por área com os corantes: Carmim Acético, Lugol e Reativo de Alexander. $\mathrm{SN}=$ Sol Nascente $\mathrm{OV}=$ Ouro Verde $\mathrm{EC}=$ Estrada Central CE=Chácara Esteio.

\begin{tabular}{cccc}
\hline \multirow{2}{*}{ Populações } & $\begin{array}{c}\text { Reativo de } \\
\text { Alexander }\end{array}$ & Carmim acético & Lugol \\
\cline { 2 - 4 } & $\%$ Viabilidade & \% Viabilidade & \% Viabilidade \\
\hline SN & $97,57 \mathrm{Aa}$ & $88,87 \mathrm{Bc}$ & $98,64 \mathrm{Ba}$ \\
OV & $99,19 \mathrm{Aa}$ & $93,68 \mathrm{Bb}$ & $98,68 \mathrm{Aa}$ \\
EC & $99,41 \mathrm{Aa}$ & $98,46 \mathrm{Aa}$ & $98,68 \mathrm{Aa}$ \\
CE & $96,6 \mathrm{Aa}$ & $99,44 \mathrm{Aa}$ & $99,32 \mathrm{Aa}$ \\
\hline Médias & 98,19 & 95,11 & 98,83 \\
\hline
\end{tabular}

Médias seguidas pelas mesmas letras maiúsculas na horizontal e minúscula na vertical não diferem estatisticamente entre si pelo teste scott knott em nível de 5\% de probabilidade.

Segundo alguns autores (JESUS et al., 2011; VEIGA et al., 2012; MELLONI, 2012), a alta viabilidade polínica além de estar relacionada com a normalidade da 
microsporogênese e microgametogênese, também está associada ao horário de coleta dos botões florais, geralmente realizado pela manhã, momento no qual as anteras começam a se tornar deiscentes e sua viabilidade encontra-se no máximo.

A coleta dos botões florais, utilizados no presente estudo, foi realizada pela manhã entre 08 e 10h, já que segundo LIMA et al., (2009) e DOS SANTOS (2013) os horários de maior viabilidade polínica para $B$. excelsa é de 06:30h até $11: 30 \mathrm{~h}$ tendo uma queda brusca a partir das 12:00h. Todos os corantes utilizados foram eficazes na distinção entre grãos de pólen viáveis e inviáveis, conforme observado na Figura 2.

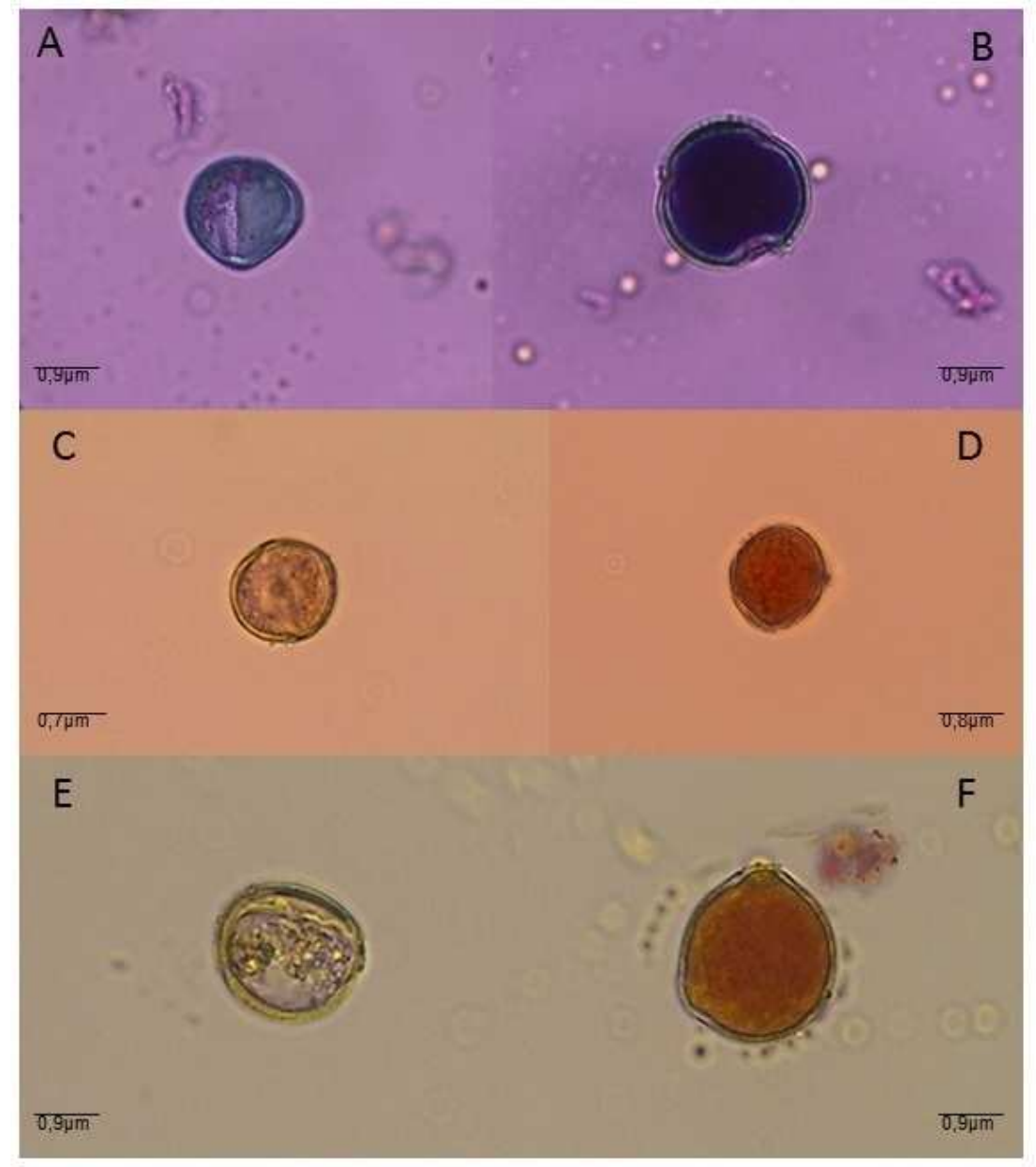

FIGURA 2- Polens de B. excelsa corados com Reativo de Alexander (A) Inviável, (B) Viável; Carmim (C) Inviável , (D) Viável; Lugol (E) Inviável (F) Viável.

FONTE: autores

Apesar do teste de Lugol apresentar a maior média (98,83\%), seguido do corante Alexander $(98,19 \%)$ e do corante Carmim Acético $(95,11 \%)$ pode-se recomendar o uso de qualquer um dos dois primeiros corantes citados, em testes rotineiros de viabilidade para a espécie $B$. excelsa, uma vez que suas médias foram maiores. Porém devido a mais fácil distinção entre grãos de pólen viáveis e inviáveis, indica-se o uso do corante Alexander, para estimar a viabilidade polínica da espécie.

Com base na comparação entre os diferentes corantes dentro de cada população, pode-se verificar na Tabela 2 que houve diferença estatística quanto à viabilidade polínica estimada pelos corantes nas populações analisadas. Para todas 
as populações a média de viabilidade foi superior a $90 \%$ independente do corante utilizado, exceto a população SN que apresentou uma média de viabilidade de $88,87 \%$ com o uso do corante carmim acético, diferindo assim das demais populações.

Esta diferença pode estar associada a diversos fatores, entre eles o ambiente em que os indivíduos foram encontrados, uma vez que segundo GUERRA et al. (2009) as condições ambientais onde as plantas estão inseridas influenciam a viabilidade do pólen. Plantas em ambientes estressantes (MAGALHÃES \& DURÃES, 2006), apresentam variações de viabilidade de pólens.

O corante Alexander utiliza uma solução tripla, por meio desse teste, o núcleo do grão de pólen viável reage com a fucsina e o pólen viável se cora de púrpura, enquanto os grãos inviáveis coram-se de verde (ALEXANDER, 1969). Ao contrário de alguns corantes utilizados para determinação da viabilidade polínica, o reativo de Alexander permite a coloração dos grãos de pólen inviáveis. Segundo ALEXANDER (1969), tal propriedade é de grande valia, visto que a utilização de corantes incapazes de corar grãos de pólen inviáveis pode levar a uma avaliação equivocada, já que pólen com parede espessa, mucilaginosa e com espículas dificultam a penetração do corante e, assim, sua coloração, podendo, levar a equivocada classificação de pólens viáveis, mas que não apresentaram coloração, como inviáveis.

No presente trabalho a estimativa da viabilidade polínica com o uso do corante Alexander obteve uma média alta, $99,41 \%$ de grãos de pólen viáveis na população EC (Tabela 1). Vale ressaltar que para a espécie $B$. excelsa, o corante de Alexander, teve uma reação tardia em relação aos demais corantes, pois este demorou de 20 a 30 minutos para reagir.

Com o uso do corante carmim acético, os pólens corados com vermelho são considerados viáveis, e os não corados e/ou mal formados, inviáveis (KEARNS \& INOUYE, 1993). A intensa coloração vermelha ocorre devido à reação com o material genético existente no citoplasma, como o DNA (PAGLIARINI \& POZZOBON, 2004).

Para a espécie $B$. excelsa o teste com carmim acético apresentou alta viabilidade, 95,11\% (Tabela 1), diferindo dos outros corantes, devido a grande amplitude observada, variando de uma população para outra com valores de $88,87 \%$ a 99,44\% (Tabela 1). Fatores bióticos e abióticos podem ter sido responsáveis por essa variação na taxa de viabilidade polínica, mas não chegaram a comprometer a fertilidade dos genótipos, visto que os mesmos apresentaram viabilidade acima de $70 \%$, o que é considerado um alto valor (SOUZA et al., 2002).

POTASCHEFF (2010) estudando a ecologia da polinização de Eschweilera nana Miers, espécie pertencente à mesma família que $B$. excelsa, também verificou uma alta viabilidade polínica $(97,92 \%)$ com o uso do carmim acético. No presente estudo, no entanto, apesar da elevada percentagem de grãos de pólen viáveis, esse corante foi o que determinou a menor média de grãos de pólens viáveis em relação aos demais corante lugol e alexander.

O método de coloração com lugol baseia-se em uma reação química entre o iodo e a molécula de amido, deixando os grãos de pólen viáveis com coloração marrom e os inviáveis, com coloração de amarela-clara à transparentes. Sendo um método indicado para espécies com grão de pólen ricos em amido (PAGLIARINI \& POZZOBON, 2004).

O teste de lugol tem sido usado para estimar a viabilidade polínica de várias espécies (CABRAL et al., 2013; TIAGO et al., 2014), no entanto, esse teste está 
associado apenas à detecção da presença de amido, que pode estar presente tanto em grãos de pólen viáveis como nos abortados. Os resultados deste estudo demonstram que os pólens de $B$. excelsa possuem amido como material de reserva e em grande quantidade, sendo, portanto considerados amiláceos, uma vez que o corante lugol reagiu com o gametófito masculino da espécie, com média geral de viabilidade de $98,83 \%$ (Tabela 1 ).

O corante lugol ao corar os grãos de pólen diferenciou de maneira considerável os poléns viáveis dos inviáveis, os pólens inviáveis com uma coloração mais transparente (Figura 2E) e os viáveis com uma cor mais intensa (Figura 2F). Mostrando - se assim que esse corante é indicado para avaliar a viabilidade polínica dessa espécie.

\section{CONCLUSÕES}

A elevada percentagem de viabilidade indica que os materiais de diferentes localidades apresentam uma divisão celular normal que resulta em grãos de polens capazes de germinar no estigma da flor, fertilizar e gerar frutos viáveis.

Independente do corante utilizado, a taxa percentual de viabilidade média geral foi alta para a espécie, mesmo havendo diferença significativa entre um dos corantes utilizados. Recomenda-se, devido a mais fácil distinção entre grãos de pólen viáveis e inviáveis o uso do corante Alexander, para estimar a viabilidade polínica de $B$. excelsa.

\section{REFERÊNCIAS}

ALVIM, P. D. O.; VON PINHO, R. G.; VON PINHO, É. V. D. R.; VEIGA, A. D.; DE OLIVEIRA, K. C.; DINIZ, R. P. Meios de cultura para germinação de grãos de pólen de milho. Agrarian, Dourados, v.5, n.17, p. 206-211, 2012.

ALEXANDER, M.P. Differential staining of aborted and noaborted pollen. Stain Tech. v.44, n.1, p.117-122, 1969.

ANGELO, H.; POMPERMAYER, R.S.; ALMEIDA, A.N.; MOREIRA, J.M.M.Á.P. O custo social do desmatamento da Amazônia brasileira: o caso da castanha-do-brasil (Bertholletia excelsa). Ciência Florestal, v. 23, n. 1, p. 183-191, 2013.

CABRAL, J. C.; ROSSI, A. A. B.; KLEIN, M. E.; VIEIRA, F. S.; DELLA GIUSTINA, L. Estimativa da viabilidade polínica em acessos de Theobroma cacao $\mathrm{L}$. baseada em testes calorimétricos. Enciclopédia Biosfera, Goiânia, v. 9, n. 17; p. 2780, 2013.

CAMARGO, F. F. Etnoconhecimento e variabilidade morfológica de castanhado-Brasil (Berthollethia excelsa Bonpl.: Lecythidaceae) em área da Amazônia matogrossense. 2011. 132 f. Dissertação (Mestrado em Ciências Florestais e Ambientais) - Faculdade de Engenharia Florestal, Universidade Federal de Mato Grosso, Cuiabá, 2010.

COSTA, P.A.D.; BALLUS, C.A.; TEIXEIRA FILHO, J.; GODOY, H.T. Fatty acids profile of pulp and nuts of Brazilian fruits. Food Science and Technology, Campinas, v. 31, n. 4, p. 950-954, 2011.

CRUZ, C.D. Programa Genes - Diversidade Genética. 1.ed. Viçosa, MG: Editora UFV, 2008, 278 p., v.1. 
DAFNI, A. Pollination ecology: a practical approach (the practical approach series). New York, Oxford: University press, 1992. 250 p.

DOS SANTOS, A.C.S.; MAUES, M.M.; CORRÊA, F.S. Viabilidade e germinação do pólen de castanheira-do-brasil (Bertholletia excelsa Bonpl. Lecythidaceae) cultivada em Tomé-Açu/PA. In: CONGRESSO NACIONAL DE BOTÂNICA, 64.; ENCONTRO REGIONAL DE BOTÂNICOS MG, BA E ES, 23., Belo Horizonte. Anais... Belo Horizonte: SBB, 2013.

GUERRA, D.; SCHIFINO-WITTMANN, M.T.; SCHWARZ, S.F. Influências ambientais na viabilidade do pólen de seis porta-enxertos de citros conduzidos a campo e em casa-de-vegetação. In: CONGRESSO BRASILEIRO DE MELHORAMENTO DE PLANTAS, 5. Guarapari, Anais... Guarapari: CBMP, 2009.

JESUS, O.N.; SOARES, T.L.; DE OLIVEIRA, E. J.; MARTINS, C. A. D.; DOS SANTOS-SEREJO, J. A. Comportamento germinativo e viabilidade polínica de Passifloras oriundos de flores coletadas em diferentes estádios e horários. In: CONGRESSO BRASILEIRO DE MELHORAMENTO DE PLANTAS, 6. Búzios-RJ, Resumos. Campos dos Goytacazes-RJ: SBMP. 2011.

KARAKAYA, D. Effects of inflorescence on pollen viability and morphologyof Strawberry (Fragaria vesca L.). Journal of Science and Technology, v. 1, p. 43-47, 2011.

KEARNS, C.A.; INOUYE, D.W. Techiniques for pollination biologists. University Press of Colorado, 1993.

LIMA, L. M. D. S., WADT, L. D. O., da SILVA, L. M., RIGAMONTE-AZEVEDO, V., \& MAUES, M. Biologia reprodutiva de castanheira (Bertholletia excelsa Bonpl) em um plantio no Acre. In: Embrapa Amazônia Oriental-Artigo em anais de congresso (ALICE). In: CONGRESSO DE ECOLOGIA DO BRASIL, 9.; CONGRESSO LATINOAMERICANO DE ECOLOGIA, 3., 2009, São Lourenço. Ecologia e o futuro da biosfera.[São Paulo]: SEB, 2009., 2010.

MAGALHÃES, P. C.; DURÃES, F. O.M. Fisiologia da produção de milho. Embrapa Milho e Sorgo, 2006.

MARTINS, K. C.; PEREIRA, T. N. S.; SOUZA, S. A. M.; COSTA, F. R. D. Meiose e viabilidade polínica em acessos de Capsicum annuum e Capsicum baccatum. Ciência Rural, Santa Maria, v. 40, n. 8, p.1746-1751, 2010.

MARTINS, L. A. R; LAVIOLA, B. G.; PRAÇA-FONTES, M. M. Viabilidade polínica de Jatropha curcas L.: uma comparação metodológica. In: CONGRESSO BRASILEIRO DE MAMONA, 5; SIMPÓSIO INTERNACIONAL DE OLEAGINOSAS ENERGÉTICAS, 2.; FÓRUM CAPIXABA DE PINHÃO MANSO, 1., 2012, Guarapari. Desafios e Oportunidades: Anais... Campina Grande: Embrapa Algodão, 2012.

MELLONI, M. L. G. Fisisologia do florescimento e viabilidade do grão-de-pólen da cana-de-açúcar (Saccharum sp.). 2012. 64 f. Dissertação (Mestrado em ENCICLOPÉDIA BIOSFERA, Centro Científico Conhecer - Goiânia, v.11 n.22; p. 31432015 
Agronomia) - Faculdade de Ciências Agrárias e Veterinárias, Universidade Estadual Paulista, 2012.

MONDAL, S., GHANTA, R. Effect of sucrose and boric acid on in vitro pollen germination of Solanum Macranthum Dunal. Indian Journal of Fundamental and Applied Life Sciences, v. 2, p. 202-206, 2012.

MORI, S. A.; PRANCE, G. T. Taxonomy, ecology, and economic botany of the Brazil nut (Bertholletia excelsa Humb And Bonpl.: Lecythidaceae). Advances in Economic Botany, v. 8, p. 130-150, 1990.

PAGLIARINI, M. S.; POZZOBON, M. T. Meiose vegetal: um enfoque para a caracterização de germoplasma. In: CURSO DE CITOGENÉTICA APLICADA A RECURSOS GENÉTICOS VEGETAIS, 2., 2004, Brasília. Anais... Brasília, 2004. p. 24-41.

POTASCHEFF, C. M. Ecologia da polinização de Eschweilera nana Miers., uma Lecythidaceae do Cerrado. Dissertação (Mestrado) - Universidade Estadual Paulista, Instituto de Biociências de Rio Claro. 2010. 53p.

SALOMÃO R. P. A castanheira: história natural e importância socioeconômica. Boletim Museu Paraense Emílio Goeldi Ciências Naturais. v.9, p. 259-266. 2014.

SMITH, N. P.; MORI, S. A.; PRANCE, G. T. Lecythidaceae in Lista de Espécies da Flora do Brasil. Jardim Botânico do Rio de Janeiro. Disponível em: http://floradobrasil.jbri.gov.br/jabot/floradobrasil/FB23424. Acesso em: 31 Mar. 2015.

SOUZA, M. M. de; PEREIRA, T. N. S.; MARTINS, E. R. Microsporogênese e microgametogênese associadas ao tamanho do botão floral e da antera e viabilidade polínica em maracujazeiro-amarelo (Passiflora edulis Sims f. flavicarpa Degener). Ciência e Agrotecnologia, Lavras. V.26, n.6, p.1209-1217, 2002.

TARIFA, J. R. Mato Grosso: clima - análise e representação cartográfica. Cuiabá: Entrelinhas, 2011. 102 p.

TIAGO, A. V.; ROCHA, V. D; TIAGO, P. V.; LIMA, J. S.; ROSSI, A. A. B. Viabilidade polínica e receptividade estigmática em variedades de mandioca (Manihot esculenta Crantz). Enciclopédia Biosfera, Goiânia, v.10, n.19, 2014.

TONINI, H. Fenologia da castanheira do brasil (Bertholletia excelsa Humb. \& Bonpl., Lecythidaceae) no sul do Estado de Roraima. Cerne, v. 17, n. 1, p. 123-131, 2011. 